\title{
EFECTIVIDAD DEL DERECHO DE LA UNIÓN EUROPEA VS. PRINCIPIO CONSTITUCIONAL DE IMPERIO DE LA LEY
}

FRANCISCO MOYA HURTADO DE MENDOZA 
SUMARIO

I. INTRODUCCIÓN. II. LA PROTECCIÓN DE CONSUMIDORES EN LOS TRATADOS Y EN LA CONSTITUCIÓN ESPAÑOLA DE 1978. III. PRINCIPIO DE EFECTIVIDAD Y DERECHO A LA TUTELA JUDICIAL EFECTIVA. 1. STJ de 18 de febrero de 2016, Finanmadrid EFC, SA, C-49/14. 2. STJ de 17 de julio de 2014, Sánchez Morcillo, C-169/14. IV. LA DIRECTIVA, INSTRUMENTO JURÍDICO PARA LA ARMONIZACIÓN. V. DIRECTIVA 93/13/CEE DEL CONSEJO, DE 5 DE ABRIL DE 1993, SOBRE CLÁUSULAS ABUSIVAS EN LOS CONTRATOS CELEBRADOS CON CONSUMIDORES. 1. Cuestión prejudicial. 2. Inferioridad del consumidor y actuación de oficio de los órganos jurisdiccionales. 2.1 STJ de 14 de junio de 2012, Banco Español de Crédito, SA, C-618/10. 3. Carácter abusivo de las cláusulas. Control de transparencia. 3.1 Sentencia de Pleno del Tribunal Supremo de 9 de mayo de 2013. 4. Artículos 6.1 y 7.1 de la Directiva. Norma de orden público y principio de efectividad. 4.1 STJ de 21 de diciembre de 2016, Francisco Gutiérrez Naranjo, asuntos acumulados C-154/15 y 307/15. VI. INTERPRETACIÓN DEL CARÁCTER ABUSIVO DE LA CLÁUSULA DE INTERESES DE DEMORA Y DE VENCIMIENTO ANTICIPADO. 1. Intereses de demora. 1.1 Cuestiones prejudiciales planteadas por el Tribunal Supremo mediante Auto de 22 de febrero de 2017. 2. Vencimiento anticipado. 2.1 Cuestiones prejudiciales planteadas por el Tribunal Supremo mediante Auto de 8 de febrero de 2017. VII. CONCLUSIONES. 


\title{
EFECTIVIDAD DEL DERECHO DE LA UNIÓN EUROPEA VS. PRINCIPIO CONSTITUCIONAL DE IMPERIO DE LA LEY
}

\author{
FRANCISCO MOYA HURTADO DE MENDOZA*
}

\section{INTRODUCCIÓN}

El Tribunal de Justicia de la Unión Europea ha dictado en los últimos cinco años numerosas Sentencias en respuesta a cuestiones prejudiciales planteadas por tribunales españoles relacionadas con la Directiva 93/13, sobre cláusulas abusivas en contratos con consumidores.

El análisis de las Sentencias pudiera llevar a considerar la protección de consumidores a nivel europeo como un proceso complejo en el que intervienen elementos diversos y que no parece dotado de suficiente previsibilidad para garantizar la seguridad jurídica de los consumidores en la contratación.

Las normas para la protección de consumidores son programáticas por establecer la consecución de un objetivo que consiste en garantizar un alto nivel de protección, con una configuración abierta tanto en la determinación de qué conseguir y cómo hacerlo.

En esa determinación intervienen por un lado la Directiva, que fija resultados mínimos a conseguir, y por otro los Estados miembros, con las normas de Derecho interno para conseguir el resultado.

La coordinación entre qué conseguir y cómo hacerlo no parece conseguida de forma suficiente, como se desprende de las Sentencias del Tribunal de Justicia que declaran no ajustadas normas sustantivas y procesales de Derecho interno a

* Magistrado en la Audiencia Provincial de Madrid. C/ Ferraz, 41. 28008 Madrid. Email: franciscomoya50@gmail.com 
la Directiva, valoración realizada por el Tribunal con aplicación del principio de efectividad.

El Tribunal de Justicia vincula el principio de efectividad con el derecho a la tutela judicial efectiva, vinculación compleja por tener contenidos y fines distintos y que no parece aclarada de forma suficiente por el Tribunal de Justicia.

La aplicación del principio de efectividad lleva al Tribunal de Justicia a trasladar la obligación de resultado a los órganos jurisdiccionales, con atribución de funciones para apreciar de oficio el carácter abusivo de cláusulas.

Esa atribución de funciones va más allá de las normas de Derecho interno que son la fuente formal que concreta la competencia y actuación de los tribunales, sometidos en su actuación al imperio de la ley.

La armonización de las normas de Derecho interno en los Estados miembros, a través de la Directiva, puso de manifiesto a la Comisión en 2008 la no obtención del objetivo pretendido de uniformidad y coherencia para la protección de consumidores frente a cláusulas abusivas, conclusión que no permite descartar la insuficiencia del instrumento jurídico utilizado para la armonización.

El Tribunal de Justicia no asume competencia para declarar si una cláusula es abusiva por corresponder dicha declaración de forma exclusiva a los órganos jurisdiccionales de los Estados miembros. No obstante lo indicado, el Tribunal de Justicia ha dictado Sentencia en la que valora el ajuste a la Directiva de criterios fijados por el Tribunal Supremo sobre los efectos de cláusula suelo declarada abusiva y ha admitido a trámite cuestiones prejudiciales sobre el criterio jurisprudencial establecido por el Tribunal Supremo para considerar abusiva la cláusula de intereses moratorios.

El Tribunal de Justicia al extender así la función de la cuestión prejudicial, para valorar el ajuste de la interpretación jurisprudencial a la Directiva, sin concretar de forma definitiva si una cláusula es abusiva y hasta donde debe llegar la protección, permite cuestionar de forma continua las normas y los criterios fijados para llevar la protección de consumidores más lejos. Como resultado de lo anterior se constata la existencia de un proceso excesivamente abierto con respuestas judiciales diferentes ante premisas fácticas idénticas.

El presente artículo analiza la repercusión de la doctrina del Tribunal de Justicia en la interpretación por los órganos jurisdiccionales de las normas de Derecho interno aplicables para la protección de consumidores frente a cláusulas abusivas, en especial en el ámbito de la tutela del derecho real de hipoteca, y cómo afecta esa construcción doctrinal al principio de seguridad jurídica y al papel del legislador en la materia. 


\section{LA PROTECCIÓN DE CONSUMIDORES EN LOS TRATADOS Y EN LA CONSTITUCIÓN ESPAÑOLA DE 1978}

La política de protección de consumidores en la Unión Europea se concretó en la Resolución del Consejo, de 14 de abril de 1975, con un programa preliminar de la Comunidad Económica Europea justificado en el artículo 2 del Tratado Constitutivo de la Comunidad Económica Europea (TCE) ${ }^{1}$, que incluía entre las misiones de la Comunidad promover una mejora cualitativa de las condiciones de vida.

Esa mejora se pretendió conseguir mediante la protección de la salud, la seguridad y los intereses económicos del consumidor, y llevó a aprobar «una política de protección e información de los consumidores» en las políticas específicas y en la aproximación de las legislaciones que afectaran a la situación del consumidor.

La protección se vinculó así al establecimiento del mercado común y a la aproximación de las legislaciones nacionales de los Estados miembros, artículo 3.h) TCE, previsión establecida en el artículo $100 \mathrm{TCE}^{2}$, en la Tercera Parte, bajo el epígrafe Política de la Comunidad, en las normas comunes del Título I, dentro del capítulo tercero, con el título «Aproximación de las legislaciones».

La primera manifestación de protección de consumidores, como objetivo político de cierta autonomía en el ámbito europeo, fue establecida en febrero de 1986 en el Acta Única Europea (AUE), por no ser hasta ese momento un ámbito de la política común y estar vinculada, como ya se dijo, al desarrollo del mercado interior ${ }^{3}$, manifestación que se concretó en el número 3 del artículo 100 $\mathrm{A}^{4}$ TCE, al establecer que las propuestas de la Comisión para la aproximación de las legislaciones se basarían en un «nivel de protección elevado».

1 «La Comunidad tendrá por misión promover, mediante el establecimiento de un mercado común y la progresiva aproximación de las políticas económicas de los Estados miembros, un desarrollo armonioso de las actividades económicas en el conjunto de la Comunidad, una expansión continua y equilibrada, una estabilidad creciente, una elevación acelerada del nivel de vida y relaciones más estrechas entre los Estados que la integran. »

2 «El Consejo adoptará, por unanimidad y a propuesta de la Comisión, directivas para la aproximación de las disposiciones legales, reglamentarias y administrativas de los Estados miembros que incidan directamente en el establecimiento o funcionamiento del mercado común. »

3 Paniagua Zurera, M. y Miranda Serrano, L. M. «La protección de los consumidores y usuarios y la irrupción del derecho de los consumidores», en Derecho (privado) de los consumidores, Marcial Pons, Madrid, 2012, p. 22.

4 «La Comisión, en sus propuestas previstas en el apartado 1, referentes a la aproximación de las legislaciones en materia de salud, seguridad, protección del medio ambiente y protección de los consumidores, se basará en un nivel de protección elevado.» 
La protección de consumidores, tras el Tratado de Lisboa (TL), se considera una competencia compartida [art. 4.2 letra f) del Tratado de Funcionamiento de la Unión Europea (TFUE) ${ }^{5}$ ] con extensión de las exigencias de protección al definir y ejecutar otras políticas y acciones de la Unión (art. 12 TFUE) ${ }^{6}$.

El artículo 169.1 TFUE $^{7}$ concreta los objetivos de la Unión para proteger los intereses de los consumidores, de forma coincidente con la Resolución del Consejo de 1975 , con fijación en el número $2^{8}$ de las medidas a adoptar para conseguir los objetivos.

En primer lugar, cita el artículo las medidas relativas a la aproximación de legislaciones para establecer el mercado interior, con remisión al artículo 114.3 TFUE 9 que concreta el objetivo de alcanzar un «nivel de protección elevado», competencia que ejerce el Consejo por el procedimiento legislativo especial, artículo 115 TFUE $^{10}$.

En segundo lugar, se citan las medidas de apoyo y complemento de las políticas llevadas a cabo por los Estados miembros, competencia atribuida al Parlamento Europeo y al Consejo, artículo 169.3 TFUE $^{11}$, a través del procedimiento legislativo ordinario, medidas que no impedirán a los Estados miembros

5 «2. Las competencias compartidas entre la Unión y los Estados miembros se aplicarán a los siguientes ámbitos principales: $[\ldots \ldots$. f) la protección de los consumidores; [......»

6 «Al definirse y ejecutarse otras políticas y acciones de la Unión se tendrán en cuenta las exigencias de la protección de los consumidores.»

7 «Para promover los intereses de los consumidores y garantizarles un alto nivel de protección, la Unión contribuirá a proteger la salud, la seguridad y los intereses económicos de los consumidores, así como a promover su derecho a la información, a la educación y a organizarse para salvaguardar sus intereses.»

8 «La Unión contribuirá a que se alcancen los objetivos a que se refiere el apartado 1 mediante: a) medidas que adopte en virtud del artículo 114 en el marco de la realización del mercado interior; b) medidas que apoyen, complementen y supervisen la política llevada a cabo por los Estados miembros.»

9 «La Comisión, en sus propuestas previstas en el apartado 1 referentes a la aproximación de las legislaciones en materia de salud, seguridad, protección del medio ambiente y protección de los consumidores, se basará en un nivel de protección elevado, teniendo en cuenta especialmente cualquier novedad basada en los hechos científicos. En el marco de sus respectivas competencias, el Parlamento Europeo y el Consejo procurarán también alcanzar ese objetivo.»

10 «Sin perjuicio del artículo 114, el Consejo adoptará, por unanimidad con arreglo a un procedimiento legislativo especial, y previa consulta al Parlamento Europeo y al Comité Económico y Social, directivas para la aproximación de las disposiciones legales, reglamentarias y administrativas de los Estados miembros que incidan directamente en el establecimiento o funcionamiento del mercado interior.»

11 «El Parlamento Europeo y el Consejo, con arreglo al procedimiento legislativo ordinario y previa consulta al Comité Económico y Social, adoptarán las medidas mencionadas en la letra b) del apartado 2.» 
mantener y adoptar otras de mayor protección, artículo $169.4 \mathrm{TFUE}^{12}$, ya que a estos últimos se reconocen competencias propias que no pueden ser ejercidas por la $\mathrm{UE}^{13}$.

El artículo 38 de la Carta de los Derechos Fundamentales de la Unión Europea (Carta) establece que «Las políticas de la Unión garantizarán un alto nivel de protección de los consumidores». En las explicaciones de la Carta se afirma basado el principio en el artículo 169 TFUE, remisión que limita el ejercicio del Derecho a las condiciones y límites de los Tratados, artículo 52 de la Carta ${ }^{14}$, Derecho de contenido similar a los que en la Constitución Española (CE) se derivan de los principios informadores del ordenamiento jurídico ${ }^{15}$.

Las normas analizadas tienen carácter programático por establecer la consecución de un objetivo que consiste en garantizar un alto nivel de protección, objetivo con una configuración abierta tanto de las condiciones de aplicación como del modelo de conducta prescrito ${ }^{16}$, coincidente con la previsión constitucional sobre protección de consumidores establecida en la Constitución de 1978, dentro de los principios rectores de la política económica y social del Capítulo III del Título primero, en los números 1 y 2 del artículo $51^{17}$, con un mandato de protección dirigido al legislador.

El artículo $51 \mathrm{CE}$, como principio rector, tiene carácter informador del ordenamiento jurídico y no contiene un derecho subjetivo susceptible de alegación directa ante los tribunales de justicia, posibilidad excluida en ausencia de norma

12 «Las medidas que se adopten en virtud del apartado 3 no obstarán para que cada uno de los Estados miembros mantenga y adopte medidas de mayor protección. Dichas medidas deberán ser compatibles con los Tratados. Se notificarán a la Comisión. »

13 Linde Paniagua, E. «El sistema de competencias de la Unión Europea de acuerdo con el Tratado de Lisboa», Revista de Derecho de la Unión Europea, n. ${ }^{\circ}$ 21-2011, pp. 167-169.

14 «2. Los derechos reconocidos por la presente Carta que tienen su fundamento en los Tratados comunitarios o en el Tratado de la Unión Europea se ejercerán en las condiciones y dentro de los límites determinados por estos.»

15 Linde Paniagua, E. «Naturaleza y caracteres de la Unión Europea», en Principios de Derecho de la Unión Europea, Uned-Colex, Madrid, 2012, p. 177.

16 Atienza Rodríguez, M. y Ruíz Manero, J. Las piezas del Derecho, Ariel Derecho, Barcelona, 1996, pp. 4-10.

17 «1. Los poderes públicos garantizarán la defensa de los consumidores y usuarios, protegiendo, mediante procedimientos eficaces, la seguridad, la salud y los legítimos intereses económicos de los mismos.

2. Los poderes públicos promoverán la información y la educación de los consumidores y usuarios, fomentarán sus organizaciones y oirán a éstas en las cuestiones que puedan afectar a aquéllos, en los términos que la ley establezca. » 
legal de desarrollo (art. 53.3 CE ${ }^{18}$ ), previsión constitucional que pretende evitar que los órganos jurisdiccionales se sitúen en la posición del legislador ${ }^{19}$.

El contenido programático de la norma hace cuestionable el enjuiciamiento de su grado de cumplimiento por el legislador por ser alcanzables los resultados a través de políticas, no susceptibles de control jurídico, por admitir diverso grado legítimo de cumplimiento, razón por la cual no se puede descartar, para algunos autores, que el enjuiciamiento de adecuación entre la ley y el objetivo a conseguir permitiría que el Tribunal Constitucional suplantara al legislador en su función estrictamente política de elegir los medios conducentes a lograr el objetivo, motivo por el que tan solo la infracción frontal del mandato finalista permitiría declarar inconstitucional la ley cuando resultara manifiesta y claramente contraria al objetivo prescrito ${ }^{20}$.

\section{PRINCIPIO DE EFECTIVIDAD Y DERECHO A LA TUTELA JUDICIAL EFECTIVA}

El Tribunal de Justicia, ante la ausencia de normas de procedimiento que regulen la forma de garantizar el respeto y aplicación de los Derechos de origen europeo, mediante el principio de autonomía institucional y de procedimiento de los Estados miembros atribuye a los ordenamientos nacionales la designación de los órganos jurisdiccionales competentes y la configuración de la regulación procesal de los recursos destinados a garantizar los Derechos de la UE ${ }^{21}$.

La jurisprudencia del Tribunal de Justicia ${ }^{22}$ ha limitado esa autonomía al establecer que los Estados miembros no son enteramente libres por estar sujeta su autonomía a las exigencias de los principios de equivalencia y efectividad, con vinculación de la autonomía institucional y de procedimiento al principio de

18 «3. El reconocimiento, el respeto y la protección de los principios reconocidos en el Capítulo tercero informarán la legislación positiva, la práctica judicial y la actuación de los poderes públicos. Sólo podrán ser alegados ante la Jurisdicción ordinaria de acuerdo con lo que dispongan las leyes que los desarrollen»

19 De Otto y Pardo, I. «Derecho constitucional. Sistema de fuentes», Universidad de Oviedo y Centro de Estudios Políticos y Constitucionales, Oviedo, 2010, p. 849.

${ }^{20}$ Cidoncha Martín, A. «La posición constitucional de los consumidores», Revista de Estudios Políticos, Septiembre de 2011, p. 128.

21 STJ de 12 de febrero de 2015, Nóra Baczó, C-567-13, apartado 41.

22 STJ de 16 de diciembre de 1976, Rewe-Zentralfinanz EG y Rewe-Zentral AG, C-33/76, apartado 5 . 
cooperación leal en la aplicación de los Derechos de la UE (art. 4.3 TUE ${ }^{23}$ ), principio conectado con la plena efectividad del Derecho de la UE y con el derecho a la tutela judicial efectiva.

El principio de equivalencia exige que las normas nacionales que regulan las acciones derivadas del Derecho de la Unión no sean menos favorables que las establecidas para el ejercicio de las acciones de Derecho interno, asegurando así idéntica protección a los Derechos surgidos en ambos ámbitos.

El principio de efectividad impone que esas normas nacionales no hagan imposible o extremadamente difícil, en la práctica, la aplicación del Derecho de la Unión, principio cuya finalidad última es asegurar la integridad, coherencia y uniformidad del ordenamiento jurídico europeo como un todo, frente a la posibilidad de que las normas nacionales impidan la efectiva aplicación de los Derechos de la Unión ${ }^{24}$.

El Tribunal de Justicia ha reconocido el principio de efectividad como un principio general de Derecho de la Unión, cuyo origen está en los principios de primacía y efecto directo, inicialmente desarrollados por el Tribunal mediante una interpretación que pretendía asegurar el efecto útil de las previsiones contenidas en los Tratados, principio cuya finalidad es asegurar el cumplimiento del Derecho de la UE por los órganos jurisdiccionales de los Estados miembros ${ }^{25}$.

La jurisprudencia del Tribunal de Justicia ${ }^{26}$ en materia de protección de consumidores afirma que el principio de efectividad implica una exigencia de tutela judicial, consagrada en el artículo 47 de la Carta $^{27}$ y que el juez nacional debe observar.

23 «3. Conforme al principio de cooperación leal, la Unión y los Estados miembros se respetarán y asistirán mutuamente en el cumplimiento de las misiones derivadas de los Tratados. Los Estados miembros adoptarán todas las medidas generales o particulares apropiadas para asegurar el cumplimiento de las obligaciones derivadas de los Tratados o resultantes de los actos de las instituciones de la Unión. Los Estados miembros ayudarán a la Unión en el cumplimiento de su misión y se abstendrán de toda medida que pueda poner en peligro la consecución de los objetivos de la Unión.»

24 Accetto, M. y Zleptnig, S. "The principle of Effectiveness: Rethinking Its Role in Community Law», European Public Law, 2005, p. 392.

${ }_{25}$ Tridimas, T. The General Principles of EU Law, Oxford European Community Law Library, Oxford, 2006, p. 419.

26 SSTJ de 17 de julio de 2014, Sánchez Morcillo, C-169/14, apartado 35; y de 6 de octubre de 2015, Orizzonte Salute - Studio Infermieristico Associato, C-61/14, apartado 48.

27 «Derecho a la tutela judicial efectiva y a un juez imparcial. Toda persona cuyos derechos y libertades garantizados por el Derecho de la Unión hayan sido violados tiene derecho a la tutela judicial efectiva respetando las condiciones establecidas en el presente artículo. Toda persona tiene derecho a que su causa sea oída equitativa y públicamente y dentro de un plazo razonable por un juez independiente e imparcial, establecido previamente por la ley. Toda persona podrá 
El derecho a la tutela judicial efectiva incluido en el artículo 47 de la Carta está vinculado al artículo 19 TUE, norma que impone a los Estados miembros establecer las vías de recurso necesarias para garantizar la tutela judicial efectiva en los ámbitos del Derecho de la Unión ${ }^{28}$.

En las explicaciones de la Carta se afirma la correspondencia del párrafo primero del artículo 47 con el artículo 13 del Convenio Europeo de Derechos Humanos $(\mathrm{CEDH})^{29}$, no obstante lo cual se considera más amplia la protección en el Derecho de la Unión por garantizar el Derecho a un recurso efectivo ante un juez, reconocido por el Tribunal de Justicia como principio general de aplicación a los Estados miembros cuando aplican los Derechos de la Unión, y del párrafo segundo con el apartado 1 del artículo $6 \mathrm{CEDH}^{30}$, derecho a un proceso equitativo.

Pese a la conexión establecida entre el principio de efectividad y el derecho a la tutela judicial efectiva, es lo cierto que la jurisprudencia del Tribunal de Justicia no parece indicar que el derecho subsuma e integre al principio. La razón está en su compleja vinculación por tener objetivos y razones diferentes, con utilización del derecho a la tutela judicial efectiva ante todo como medio para conectar su regulación con el $\mathrm{CEDH}^{31}$, relación que no permite tampoco descartar la perspectiva que atribuye al principio de efectividad una consideración global de contenido más amplio para garantizar el efecto útil de los Derechos surgidos en el ámbito de la UE y en el cual se incluye, como una de sus manifestaciones, el derecho a la tutela judicial efectiva ${ }^{32}$.

hacerse aconsejar, defender y representar. Se prestará asistencia jurídica gratuita a quienes no dispongan de recursos suficientes siempre y cuando dicha asistencia sea necesaria para garantizar la efectividad del acceso a la justicia.»

${ }^{28}$ López Escudero, M. «Título VI Justicia», en Carta de los Derechos Fundamentales de la Unión Europea. Comentario artículo por artículo, Fundación BBVA, Bilbao, 2008, p. 742.

29 «Toda persona cuyos derechos y libertades reconocidos en el presente Convenio hayan sido violados tiene derecho a la concesión de un recurso efectivo ante una instancia nacional, incluso cuando la violación haya sido cometida por personas que actúen en el ejercicio de sus funciones oficiales». Sobre el artículo 13 del CEDH, vid. GonZÁlez García, J. M. ${ }^{a}$, «La protección de los derechos fundamentales en la Constitución Europea: a propósito del derecho a un recurso efectivo, del artículo 13 del Convenio Europeo para la Protección de los Derechos Fundamentales y las Libertades Públicas», en Garantías fundamentales del Proceso Penal en el Espacio Judicial Europeo (coords. Oliva Santos, Armenta Deu y Calderón Cuadrado), Colex, Madrid, 2007, pp. 255-272.

30 «Toda persona tiene derecho a que su causa sea oída equitativa, públicamente y dentro de un plazo razonable, por un Tribunal independiente e imparcial, establecido por la Ley...»

31 BEKA, A. «The role of the national courts for the protection of the consumers: a European Law perspective», en Reforma del proceso de ejecución hipotecaria y jurisprudencia del Tribunal de Justicia de la Unión Europea, Cuadernos Digitales de Formación, CGPJ, 2014, p. 6.

32 Accetto, M. y Zleptnig, S., op cit., p. 388. 
1. STJ de 18 de febrero de 2016, Finanmadrid EFC, SA, C-49/14

La compleja relación entre el derecho y el principio fue puesta de manifiesto por el Abogado General Szpunar en las Conclusiones presentadas el 11 de noviembre de 2015, asunto resuelto por la STJ de 18 de febrero de 2016 (Finanmadrid EFC, SA, C-49/14) en respuesta a cuestiones prejudiciales planteadas por órgano jurisdiccional español.

Las cuestiones primera y segunda estaban referidas a la compatibilidad de las normas de la Ley de Enjuiciamiento Civil (LEC) con la Directiva 93/13. La primera, por no prever de forma imperativa los artículos 815 y 816 de la LEC, en proceso monitorio, la intervención del juez para controlar la posible existencia de cláusulas abusivas en el contrato que da lugar al requerimiento de pago al deudor consumidor. La segunda, por no permitir los artículos 551 y 552 de la LEC, en el proceso de ejecución de título judicial posterior, título identificado con el Decreto dictado por el Sr. Secretario que puso fin al monitorio antecedente, que el juez de la ejecución pueda analizar de oficio el posible carácter abusivo de las cláusulas contenidas en el contrato.

El Tribunal de Justicia afirmó la oposición de la Directiva 93/13 a la normativa nacional que no permite al juez que conoce de la ejecución de un requerimiento de pago previo, realizado en proceso monitorio, apreciar de oficio el carácter abusivo de cláusula en contrato celebrado entre profesional y consumidor, cuando la autoridad que conoció la petición de monitorio antecedente carecía de competencia para realizar tal apreciación, conclusión fundada en la aplicación del principio de efectividad.

Las cuestiones tercera y cuarta estaban referidas a la compatibilidad de las mismas normas de la LEC con el derecho a la tutela judicial efectiva, artículo 47 de la Carta, a las que no dio respuesta el Tribunal por razones formales al no contener el Auto de remisión indicaciones precisas.

El Abogado General, en sus conclusiones, sí analizó la compatibilidad de las normas procesales cuestionadas con el artículo 47 de la Carta, con especial referencia, por lo que aquí interesa, a las afirmaciones siguientes.

- El Juez nacional debe respetar las exigencias de tutela judicial efectiva, tal como ésta se halla garantizada en el artículo 47 de la Carta, en oposición al criterio expresado por el gobierno alemán sobre la no aplicabilidad de la Carta a las normas procesales regidas por el principio de autonomía procesal del Derecho nacional. De no ser así, si los Estados miembros pudieran eludir respetar el artículo 47 de la Carta invocando el principio de autonomía del Derecho proce- 
sal nacional, la tutela judicial efectiva de los derechos dimanantes del Derecho de la Unión quedaría vacía de contenido ${ }^{33}$.

- Respecto de la relación entre el principio de efectividad y el artículo 47 de la Carta «....el Tribunal de Justicia aún no ha tenido la ocasión de esclarecer la forma en que se articulan las exigencias resultantes del artículo 47 de la Carta y aquellas, muy similares, derivadas de los principios de equivalencia y de efectividad. De hecho, este último principio en particular se traduce también en el hecho de que impone a los Estados miembros la obligación general de garantizar la tutela judicial de los derechos dimanantes del Derecho de la Unión, por lo que podría suscitarse la cuestión de saber si el artículo 47 de la Carta viene a añadirse al principio de efectividad o lo sustituye» ${ }^{34}$.

- La Directiva 93/13 y el principio de efectividad se oponen a las normas nacionales analizadas, conclusión a la que no permite llegar el artículo 47 de la Carta, porque el grado de tutela judicial de los Derechos que la Directiva 93/13 confiere a los consumidores es mayor que el derivado del artículo 47 de la $\operatorname{Carta}^{35}$.

- La exigencia de control de oficio es una particularidad de los litigios caracterizados por la existencia de desequilibrio entre partes, exigencia vinculada al artículo 6.1 de la Directiva. El artículo 47 de la Carta no se opone a un procedimiento nacional simplificado que permita solo valorar las pretensiones de fondo en caso de oposición del demandado y que, por lo tanto, no permita al juez examinar de oficio las cláusulas contractuales cuando no exista oposición ${ }^{36}$.

- El artículo 47 de la Carta no se opone a una normativa nacional que impida al juez de ejecución controlar de oficio el título ejecutivo y apreciar de oficio los vicios del proceso monitorio, siempre que disponga de una vía de recurso efectiva que le permita oponerse al requerimiento de pago y alegar una eventual vulneración de su derecho de defensa ${ }^{37}$.

\section{STJ de 17 de julio de 2014, Sánchez Morcillo, C-169/14}

Como ejemplo de valoración de norma nacional con aplicación del artículo 47 de la Carta está la STJ de 17 de julio de 2014 (Sánchez Morcillo, C-169/14)

\footnotetext{
33 Apartados 83 y 84.

34 Apartado 85.

35 Apartado 90.

36 Apartados 92 y 93.

37 Apartado 97.
} 
que analizó la nueva redacción dada al art.695.4 ${ }^{38}$ LEC con motivo de la reforma introducida por la Ley 1/2013, de 14 de mayo.

La nueva redacción del artículo solo permitía recurrir en apelación el Auto que ordenara el sobreseimiento de la ejecución hipotecaria o la inaplicación de cláusula abusiva por la posible estimación de motivo de oposición, posibilidad de recurrir no contemplada para el caso de desestimación del motivo de oposición alegado por el consumidor.

El Tribunal de Justicia afirma que la nueva redacción dada al artículo 695.4 LEC es contraria al principio de igualdad de armas, principio que forma parte del derecho a la tutela judicial efectiva garantizado en el artículo 47 de la Carta, previsión normativa contraria al concepto de proceso justo que implica la obligación de ofrecer a cada una de las partes una oportunidad razonable de formular sus pretensiones en condiciones que no la coloquen en una situación de manifiesta desventaja.

De lo expresado parece desprenderse que pese a la conexión del principio de efectividad con el derecho a la tutela judicial efectiva, los contenidos de uno y otro no son coincidentes con distintas perspectivas de valoración y que pueden llevar a considerar la norma incompatible con el principio y no con el derecho.

En cualquier caso, la aplicación del principio de efectividad en la jurisprudencia del Tribunal de Justicia tiene una incidencia legislativa por valorar las normas de Derecho interno vinculadas a la protección de consumidores, y una incidencia judicial por obligar a los órganos jurisdiccionales, en caso de insuficiencia normativa, a intervenir de forma positiva para garantizar la protección.

\section{LA DIRECTIVA, INSTRUMENTO JURÍDICO PARA LA ARMONIZACIÓN}

Los Tratados concretan la directiva como el instrumento jurídico para la armonización de las legislaciones de los Estados miembros.

Como es sabido, las directivas, según el artículo 288 TFUE $^{39}$, imponen a los Estados miembros una obligación de resultado que lleva implícita la exigencia

38 «4. Contra el auto que ordene el sobreseimiento de la ejecución o la inaplicación de una cláusula abusiva podrá interponerse recurso de apelación. Fuera de estos casos, los autos que decidan la oposición a que se refiere este artículo no serán susceptibles de recurso alguno y sus efectos se circunscribirán exclusivamente al proceso de ejecución en que se dicten.»

39 «La directiva obligará al Estado miembro destinatario en cuanto al resultado que deba conseguirse, dejando, sin embargo, a las autoridades nacionales la elección de la forma y de los medios.» 
de adoptar las medidas necesarias para alcanzarlo, con vinculación de los efectos jurídicos de las directivas a la norma nacional de incorporación ${ }^{40}$ y dejando a las autoridades nacionales la elección de la forma y los medios.

La aproximación de legislaciones en materia de consumo siguió, de forma preferente, el modelo de armonización mínima, con directivas ${ }^{41}$ que fijan objetivos mínimos para la protección y obligan a los Estados miembros a adoptar disposiciones adecuadas y eficaces para conseguir el resultado, directivas que no impiden a los Estados miembros asegurar una protección más amplia del consumidor.

A las directivas con mínimos de armonización se añadieron directivas con objetivos de armonización completa ${ }^{42}$, ante las que los Estados miembros deben ofrecer de forma exacta el mismo nivel de protección exigido por la Directiva ${ }^{43}$, con menor margen de autonomía para su incorporación al ordenamiento interno.

La directiva, como instrumento jurídico dirigido a la obtención de un resultado, presenta dificultad de coordinación de todas las partes implicadas por las siguientes razones.

- Por instar a la Comisión, en su función de iniciativa normativa, artículo 17.2 del Tratado de la Unión Europea (TUE) ${ }^{44}$, a alcanzar un nivel elevado de protección.

- Por corresponder al Consejo la fijación de los objetivos y resultados a conseguir mediante mínimos o máximos de armonización.

- Por intervenir los Estados miembros en cómo alcanzar los resultados a través de las normas de incorporación en el ordenamiento jurídico interno.

- Por asumir el Tribunal de Justicia la función de valorar si las previsiones normativas de los Estados miembros permiten alcanzar el resultado fijado en las directivas.

- Y por tener competencia, en última instancia, los órganos jurisdiccionales de los Estados miembros para garantizar la protección.

40 Mangas Martín, A y Liñán Nogueras, D. J. Instituciones y Derecho de la Unión Europea, Tecnos, Madrid, 2012, pp. 373-375.

41 Entre otras, directiva sobre publicidad engañosa (1984), sobre contratos negociados fuera de establecimientos comerciales (1985) y sobre créditos al consumo (1987).

42 Directiva 85/374, en materia de responsabilidad por los daños causados por productos defectuosos.

43 Trstenjak, V y Beysen, E. «European consumer protection law: curia semper dabit remedium?» Kluwer Law Internacional, 2011, p. 110.

44 «Los actos legislativos de la Unión sólo podrán adoptarse a propuesta de la Comisión, excepto cuando los Tratados dispongan otra cosa. Los demás actos se adoptarán a propuesta de la Comisión cuando así lo establezcan los Tratados.» 
Las dificultades de coordinación fueron puestas de manifiesto por la revisión del acervo de consumo a nivel europeo, a instancia de la Comisión, entre cuyos trabajos destaca el encargo realizado a un grupo de expertos para efectuar un análisis comparativo de la incorporación de diversas directivas de consumo en los Estados miembros, el EC Consumer Law Compendium (febrero 2008).

Los expertos, en sus conclusiones, afirmaron la existencia de incoherencias y ambigüedades en los contenidos de las directivas analizadas, entre otras la Directiva 93/13, contenidos que hacen difícil la incorporación y su correcta aplicación por los órganos jurisdiccionales. Refieren también las diferencias de las normas de incorporación con contenidos distintos respecto de las cuestiones no contempladas expresamente en las directivas, y el modo distinto en que los Estados interpretan la cláusula de mínimos de armonización.

A los problemas de coordinación expuestos se añade el carácter incompleto de las directivas por no tener efecto directo para su aplicación, limitación que ha suplido la jurisprudencia del Tribunal de Justicia al reconocer efecto directo vertical en su exigencia de aplicabilidad por el particular frente al Estado, por ser este el obligado a la incorporación y a la integración efectiva de la norma en el ordenamiento jurídico interno, siempre que la previsión de contenido de la directiva cuya aplicación se pretende sea incondicional y precisa ${ }^{45}$.

Distinto criterio ha mantenido el Tribunal de Justicia por excluir efecto directo horizontal de las directivas para su posible invocación y aplicación en las relaciones jurídicas entre particulares ${ }^{46}$, ámbito en el que se desarrolla principalmente la contratación con consumidores.

La exclusión se justifica en ser los Estados miembros los únicos destinatarios obligados al cumplimiento de las directivas, porque de reconocer efecto directo horizontal la directiva se transformaría en reglamento, con la incidencia que eso podría tener en el reparto de competencias entre la UE y los Estados miembros, y por el principio de seguridad jurídica, que podría verse cuestionado si un particular se encontrara sujeto a una obligación que está en contradicción y se opone a previsión normativa vigente en su legislación nacional ${ }^{47}$.

El Tribunal de Justicia ha suplido esa exclusión mediante la interpretación conforme, que obliga a los órganos jurisdiccionales a tomar en consideración

45 STJ de 19 de enero de 1982, Becker, C-8/81, apartados 24 y 25.

46 SSTJ de 14 de julio de 1994, Faccini Dori, C-91/92, apartados 20,22 y 23, y de 7 de marzo de 1996, El Corte Inglés, C-192/94, apartado 21.

47 Millet, T. «El efecto directo de las directivas: ¿hacia un reconocimiento del efecto directo horizontal?» en La articulación entre el Derecho comunitario y los Derechos nacionales: algunas zonas de fricción, Estudios de Derecho Judicial, Consejo General del Poder Judicial (CGPJ), Madrid, 2007 , p. 16. 
todas las normas del Derecho nacional y a interpretarlas, en la medida de lo posible, a la luz de la letra y de la finalidad de la directiva aplicable para llegar a una solución conforme con el objetivo perseguido por ésta ${ }^{48}$, posibilidad que pretende excluir la aplicación mediante una interpretación contraria a la ley ${ }^{49}$.

De esa forma, la directiva tiene un contenido útil por servir de apoyo a los intereses del justiciable. Ahora bien, esa posibilidad interpretativa del Derecho nacional puede provocar una gran diversidad de aplicación de un Estado miembro a otro y también entre los diferentes órganos jurisdiccionales de un mismo Estado ${ }^{50}$.

Cuando la interpretación conforme exige un gran esfuerzo interpretativo, más allá de su tenor literal, hace inevitable que la norma interpretada se aleje de las exigencias de seguridad jurídica impuestas por el Tribunal de Justicia, en cuanto al conocimiento por los particulares de los Derechos reconocidos por la UE, situación que puede llevar a que permanezcan en el tiempo previsiones normativas incompatibles con el Derecho de la UE hasta que el legislador modifica la norma ${ }^{51}$.

\section{DIRECTIVA 93/13/CEE DEL CONSEJO, DE 5 DE ABRIL DE 1993, SOBRE CLÁUSULAS ABUSIVAS EN LOS CONTRATOS CELEBRADOS CON CONSUMIDORES}

La incorporación de la Directiva 93/13 al ordenamiento interno tuvo lugar mediante la Ley 7/1998, de 13 de abril, sobre Condiciones Generales de la Contratación (LCGC), incorporación que debe ser puesta en conexión con el Real Decreto Legislativo 1/2007, de 16 de noviembre, por el que se aprobó el Texto Refundido de la Ley General para la Defensa de los Consumidores y Usuarios y otras Leyes complementarias (TRLGDCU), cuya finalidad fue refundir en un solo texto las normas promulgadas para incorporar las directivas de consumo y para aclarar, regularizar y armonizar los textos legales vigentes en la materia, norma a partir de la cual la LCGC mantuvo su vigencia con carácter supletorio al TRLGDCU.

48 Sentencia del TJ de 21 de enero de 2015, Unicaja Banco, SA y Caixabank, S.A., asuntos acumulados C-482/13, C-484/13, C-485/13 y C-87/13, apartado 38.

49 STJ de 15 de enero de 2014, Association de médiation sociale, C176/12, apartado 39.

50 Ruiz-Jarabo Colomer, D. «Las fuentes del derecho comunitario», en Derecho Social Comunitario, Cuadernos de Derecho Judicial, CGPJ, Madrid, 1992, p. 16.

51 Alonso García, R. Sistema jurídico de la Unión Europea, Aranzadi, Pamplona, 2012, p. 293. 
Esta Directiva fue la primera que se aprobó para su aplicación general a todas las modalidades de contratación en las que intervinieran un profesional y un consumidor $^{52}$. Ahora bien, lo que establece son mínimos de armonización, el soporte básico de protección mejorable y susceptible de ampliación por tener libertad los Estados miembros para mantener o introducir normas más favorables para los consumidores como establece su artículo $8^{53}$.

\section{Cuestión prejudicial}

La limitación normativa de las directivas de mínimos ha hecho precisa una intervención permanente del Tribunal de Justicia mediante respuesta a cuestiones prejudiciales planteadas por los órganos jurisdiccionales de los Estados miembros.

La finalidad de la cuestión prejudicial, artículo 267 TFUE, es posibilitar que el órgano jurisdiccional nacional ante el que se sustancia un litigio que requiera la aplicación de una norma de la Unión, pueda dirigirse al Tribunal de Justicia para solicitar que interprete o determine la validez de la norma, tras lo cual el juez nacional resolverá el litigio principal.

La cuestión prejudicial responde al modelo jurisdiccional de la Unión, de carácter descentralizado, en el que el desarrollo y ejecución de los Derechos de origen europeo se realiza por los Estados miembros.

El modelo está basado en el principio de cooperación con el Tribunal de Justicia $^{54}$, que permite a dicho Tribunal garantizar la uniformidad de la interpretación y aplicación del Derecho de la $\mathrm{UE}^{55}$, dejando a los jueces nacionales su aplicación efectiva.

52 Dice en su considerando diez lo siguiente: «Considerando que puede obtenerse una protección más eficaz del consumidor mediante la adopción de normas uniformes sobre cláusulas abusivas; que tales normas deben aplicarse a todos los contratos celebrados entre un profesional y un consumidor;......»

53 «Los Estados miembros podrán adoptar o mantener en el ámbito regulado por la presente Directiva, disposiciones más estrictas que sean compatibles con el Tratado, con el fin de garantizar al consumidor un mayor nivel de protección.»

54 Ugartemendia ECEIZAbarrena, J. I. «La tutela judicial de los derechos fundamentales en el ámbito de aplicación nacional del Derecho de la Unión Europea. Recientes acotaciones del Tribunal de Justicia y del Tribunal Constitucional español». Teoría y Realidad Constitucional, núm. 32-2013, p. 396.

55 Bacigalupo Saggese, M. «El sistema jurisdiccional de la Unión Europea», en Principios de Derecho de la Unión Europea, Uned-Colex, Madrid, 2012, p. 468. 
La interpretación y aplicación uniforme permite extender el elemento común de la existencia de la norma a la fase de ejecución material por los órganos jurisdiccionales de los Estados miembros ${ }^{56}$.

La finalidad de la cuestión prejudicial es hacer posible la interpretación uniforme del Derecho de la Unión por parte del Tribunal de Justicia, sin extender esa competencia a formular juicios sobre la compatibilidad entre el Derecho Europeo y el Derecho nacional. No obstante lo indicado, es incuestionable que la interpretación de las normas europeas puede tener repercusión inmediata sobre dicha compatibilidad, situación que permite extender la función de la cuestión prejudicial como vía procesal a través de la cual el Tribunal de Justicia controla el respeto de las normas europeas por el Derecho de los Estados miembros ${ }^{57}$.

La jurisprudencia del Tribunal de Justicia analizada, en materia de protección de consumidores, no parece limitada a la finalidad de interpretar la norma europea por extender su función para valorar la adecuación de la norma interna a la Directiva, por existir pronunciamientos que controlan también la adecuación de la interpretación jurisprudencial a la Directiva, por establecer criterios de interpretación para ser utilizados por los órganos jurisdiccionales y, también, por imponer a los órganos jurisdiccionales la obligación de actuar para conseguir los resultados de la Directiva con independencia de las previsiones legales de Derecho interno que limitan su actuación.

La justificación de esa extensión podría estar relacionada con el modelo descentralizado que caracteriza la aplicación del Derecho de la UE, a través de la actuación de los Estados miembros, pues de no ser efectiva la aplicación de los derechos surgidos a nivel europeo su contenido tendría tan solo carácter virtual.

\section{Inferioridad del consumidor y actuación de oficio de los órganos jurisdiccionales}

Los considerandos ocho y nueve de la Directiva fijan el objetivo de proteger a los consumidores contra cláusulas abusivas, por estar el consumidor frente al vendedor o prestador de servicios en situación de inferioridad tanto en su capacidad de negociación como de información, objetivo de protección reiterado de forma permanente por el Tribunal de Justicia ${ }^{58}$.

\footnotetext{
56 Alonso García, R. «El Juez español y el Derecho Comunitario», CGPJ, Madrid, 2003, p. 216.

57 Bacigalupo Saggese, M., op. cit, p. 547.

58 SSTJ 26 de octubre de 2006, Mostaza Claro, C-168/05, apartado 25; de 6 de octubre de 2009, Asturcom Telecomunicaciones, S.L., C-40/08, apartado 29; de 3 de junio de 2010, Caja 
La inferioridad del consumidor ha llevado al Tribunal de Justicia, de forma reiterada, a declarar que la situación de desequilibrio entre el consumidor y el profesional sólo puede compensarse mediante una intervención positiva, ajena a las partes del contrato, por el juez nacional que conoce del litigio, quien deberá apreciar de oficio el carácter abusivo de una cláusula contractual incluida en el ámbito de aplicación de la Directiva 93/1359.

La actuación, afirma el Tribunal de Justicia ${ }^{60}$, se corresponde con el papel que el Derecho de la Unión atribuye a los órganos jurisdiccionales que no se limita a la mera facultad de pronunciarse sobre la naturaleza eventualmente abusiva de una cláusula contractual, sino que incluye la obligación de examinar de oficio la cuestión tan pronto como disponga de los elementos de hecho y de Derecho necesarios para ello.

La intervención positiva impuesta por el Tribunal de Justicia es una obligación que va más allá de las competencias atribuidas en Derecho interno a los órganos jurisdiccionales, sujetos en su actuación al imperio de la ley, artículo $117 \mathrm{CE}^{61}$, y al principio de legalidad procesal, artículo $1 \mathrm{LEC}^{62}$, cuando la norma procesal expresamente no permite esa actuación positiva de oficio.

La asignación de tareas y funciones por el Tribunal de Justicia a los órganos jurisdiccionales, con la finalidad de garantizar la aplicación efectiva de los Derechos de la Unión, para algunos autores, no tiene en sí misma fundamento para atribuir competencia y poder que legitime la actuación, por ser fuente formal de la competencia y autoridad de los órganos jurisdiccionales la norma nacional ${ }^{63}$.

La actuación de oficio impuesta por el Tribunal de Justicia da lugar, en la práctica, a criterios de interpretación diferentes ante premisas fácticas idénticas,

de Ahorros y Monte de Piedad de Madrid, C-484/08, apartado 27; y de 15 de marzo de 2012, Jana Perenicová y Vladslava Perenic, C-453/10, apartado 27.

59 SSTJ de 27 de junio de 2000, Océano Grupo Editorial SA, asuntos acumulados C-240/98 y C-244/98, apartado 26; de 21 de noviembre de 2002, Cofidis, SA, C-473/00, apartados 31 y 32; de 26 de octubre de 2006, Mostaza Claro, C-168/05, apartados 26 y 27; de 6 de octubre y 4 de junio de 2009, Asturcom Telecomunicaciones, SL, C-40/08 apartados 31 y 32 y Pannon GSM Zrt, C-243/08 apartado 23; 21 de abril de 2016, Ernst Georg Radlinger y Helena Radlingerová, C-377/14, apartados 52 y 53.

${ }^{60}$ STJ de 30 de mayo de 2013, Dirk Frederik Asbeek Brusse, C-488/11, apartado 41.

${ }^{61}$ «La justicia emana del pueblo y se administra en nombre del Rey por Jueces y Magistrados integrantes del poder judicial, independientes, inamovibles, responsables y sometidos únicamente al imperio de la ley.»

62 «En los procesos civiles, los tribunales y quienes ante ellos acudan e intervengan deberán actuar con arreglo a lo dispuesto en esta Ley.»

63 Prechal, S. «National Courts in EU Judicial Structures», Yearbook of European Law, 1/2006, p. 19. 
con la incidencia que eso tiene en la seguridad jurídica desde la perspectiva de previsibilidad del Derecho.

2.1 STJ de 14 de junio de 2012, Banco Español de Crédito, SA, C-618/10.

Como ejemplo se puede citar la STJ de 14 de junio de 2012 (Banco Español de Crédito, SA, C-618/10).

La Sentencia declaró que el artículo 815 de la Ley de Enjuiciamiento Civil (LEC 2000) se oponía a la Directiva 93/13, por no permitir que el juez que conoce de una demanda en proceso monitorio pueda examinar de oficio el carácter abusivo de una cláusula cuando el consumidor no haya formulado oposición, declaración que dio lugar a criterios de interpretación distintos por los órganos jurisdiccionales.

Por un lado, el criterio que suple la insuficiencia normativa mediante la inadmisión, ab initio, de la demanda de proceso monitorio frente a consumidor, por no ser posible que los órganos judiciales puedan crear trámites procesales no previstos.

Por otro, el que sí considera posible la admisión a trámite de la demanda por ser posible interpretar el proceso monitorio a la luz del tenor literal y de la finalidad de la Directiva, siempre que una vez admitida la demandada el órgano jurisdiccional valore el posible carácter abusivo de las cláusulas que dan contenido a la reclamación ${ }^{64}$.

La interpretación de la norma interna en la forma expuesta lleva implícita la atribución de competencia no prevista expresamente, actuación de oficio, y la creación de un trámite procesal de audiencia tampoco previsto.

La cuestión fue tratada en la «Jornada sobre las repercusiones de la doctrina del TJUE en materia de clausulas abusivas en los procedimientos de ejecución bipotecaria con especial referencia al régimen transitorio», celebrada en Madrid el 8 de mayo de 2013, con asistencia de Magistrados de la Sala 1. ' Tribunal Supremo, Tribunales Superiores de Justicia, Audiencias Provinciales y Juzgados civiles y mercantiles, en la que se establecieron criterios de contenido orientativo con referencia expresa a la posible apreciación de oficio de cláusulas abusivas en supuestos de solicitud inicial de proceso monitorio ${ }^{65}$.

64 Auto de Pleno jurisdiccional de la Audiencia Provincial de Madrid de 4 de marzo de 2013.

65 «En el proceso monitorio, sin perjuicio de las competencias del Secretario Judicial, corresponde al juez el examen del carácter abusivo de una cláusula incluida en el documento que sustente la reclamación del crédito. Este examen se realizará en la fase de admisión de la solicitud. Si el juez considera que la cláusula puede ser abusiva lo pondrá en conocimiento del solicitante, especificando la cláusula afectada y le concederá un plazo de cinco días para formular alegaciones. 
La previsión normativa incompatible con la Directiva 93/13 se mantuvo en el tiempo hasta que el legislador, mediante la Ley 42/2015, de 5 de octubre, dio cumplimiento a la Sentencia del Tribunal de Justicia al dar nueva redacción al artículo 815 (LEC 2000), con la inclusión del apartado $4^{66}$ que permite al juez controlar la eventual existencia de cláusulas abusivas en los contratos en que se basen los procedimientos monitorios que se dirijan contra consumidores.

\section{Carácter abusivo de las cláusulas. Control de transparencia}

El Tribunal de Justicia, como establece en jurisprudencia reiterada, no tiene competencia para determinar si una cláusula es abusiva, pronunciamiento declarativo final que incumbe de forma exclusiva a los órganos jurisdiccionales con atención a las circunstancias del caso concreto ${ }^{67}$.

La consideración de una cláusula como abusiva se concreta en el artículo 3.1 ${ }^{68}$, que establece como presupuesto ser una cláusula que no haya sido negociada individualmente, cualidad atribuible a la que haya sido redactada previamente, artículo $3.2^{69}$, sin posibilidad para el consumidor de haber podido influir en su contenido, con expresa mención de los contratos de adhesión.

El carácter abusivo de la cláusula, con ese presupuesto, remite su valoración a los conceptos de «buena fe» $\mathrm{y}$ «desequilibrio importante» en detrimento del consumidor, conceptos que para el Tribunal de Justicia delimitan en abstracto el carácter abusivo y que obligan al juez nacional a comprobar si el profesional

Si como consecuencia de la apreciación de la cláusula abusiva procediera la reclamación por una cantidad inferior a la inicial, se procederá conforme establece el artículo 815.3 de la Ley de Enjuiciamiento Civil.»

66 «Si la reclamación de la deuda se fundara en un contrato entre un empresario o profesional y un consumidor o usuario, el secretario judicial, previamente a efectuar el requerimiento, dará cuenta al juez para que pueda apreciar el posible carácter abusivo de cualquier cláusula que constituya el fundamento de la petición o que hubiese determinado la cantidad exigible.»

${ }^{67}$ STJ de 21 de marzo de 2013, RWE Vertrieb AG, C-92/11, apartado 48.

68 «Las cláusulas contractuales que no se hayan negociado individualmente se considerarán abusivas si, pese a las exigencias de la buena fe, causan en detrimento del consumidor un desequilibrio importante entre los derechos y obligaciones de las partes que se derivan del contrato.»

69 «Se considerará que una cláusula no se ha negociado individualmente cuando haya sido redactada previamente y el consumidor no haya podido influir sobre su contenido, en particular en el caso de los contratos de adhesión. El hecho de que ciertos elementos de una cláusula o que una cláusula aislada se hayan negociado individualmente no excluirá la aplicación del presente artículo al resto del contrato si la apreciación global lleva a la conclusión de que se trata, no obstante, de un contrato de adhesión. El profesional que afirme que una cláusula tipo se ha negociado individualmente asumirá plenamente la carga de la prueba.» 
podía estimar razonablemente que, tratando de manera leal y equitativa con el consumidor, éste aceptaría una cláusula de ese tipo en una negociación individual $^{70}$.

Ese contenido debe ser puesto en conexión con la regulación legal o el fin del contrato y no con los elementos esenciales como cosa y precio ${ }^{71}$, valoración a realizar desde una perspectiva jurídica que compare los derechos y obligaciones de las cláusulas predispuestas con los derechos y obligaciones previstos en el Derecho interno, con especial atención a las circunstancias del caso concreto, artículo 4.1 de la Directiva ${ }^{72}$.

El artículo 3.3 remite al Anexo, que contiene una lista indicativa y no exhaustiva de cláusulas que pueden ser declaradas abusivas, con un total de 17 supuestos entre los cuales se incluye la que tenga por objeto imponer al consumidor que no cumpla sus obligaciones una indemnización desproporcionadamente alta.

El artículo 4.2 excluye la posible consideración del carácter abusivo de las cláusulas relativas a la definición del objeto principal del contrato, a la adecuación entre precio y retribución y a los servicios o bienes que hayan de proporcionarse como contrapartida, siempre que dichas cláusulas se redacten de manera clara y comprensible, exigencia de forma que se concreta en el artículo 5, respecto de las cláusulas redactadas por escrito, con previsión, en caso de duda sobre el sentido de una cláusula, de prevalecer la interpretación más favorable para el consumidor, circunstancia que permite considerar su carácter abusivo no por el contenido sino por la forma.

La exclusión de control del carácter abusivo de dichas cláusulas se justifica por el Tribunal de Justicia por no existir baremo o criterio jurídico que pueda delimitar y orientar el control de adecuación entre el precio o la retribución prevista y los servicios o bienes que hayan de proporcionarse como contrapartida ${ }^{73}$.

70 STJ de 26 de enero de 2017, Banco Primus, S.A., C-421/14, apartados 58 y 60.

71 Miquel González de Audicana, J. M. «Cláusulas abusivas», en Protección del consumidor en las Directivas comunitarias y en las normas nacionales desde la perspectiva de la jurisprudencia del Tribunal de Justicia de la Unión Europea, Cuadernos Digitales de Formación, CGPJ, Madrid, 2015, p. 42.

72 «Sin perjuicio del artículo 7, el carácter abusivo de una cláusula contractual se apreciará teniendo en cuenta la naturaleza de los bienes o servicios que sean objeto del contrato y considerando, en el momento de la celebración del mismo, todas las circunstancias que concurran en su celebración, así como todas las demás cláusulas del contrato, o de otro contrato del que dependa.»

73 STJ de 26 de febrero de 2015, Bogdan Matei e Ioana Ofelia Matei, C-143/13, apartado 55. 
3.1 Sentencia de Pleno del Tribunal Supremo de 9 de mayo de 2013

La Sentencia dio respuesta a la acción de cesación instada por asociación de consumidores frente a entidades bancarias respecto de la inclusión de cláusulas abusivas en condiciones generales de la contratación, entre ellas cláusula suelo en préstamos hipotecarios.

La Sentencia, tras analizar el control que permite la Directiva sobre las cláusulas que definen el objeto principal del contrato, «que se redacten de manera clara y comprensible», extendió su contenido más allá de un mero control de transparencia documental o gramatical al exigir también transparencia que permita al consumidor tener perfecto conocimiento de las consecuencias económicas y jurídicas implícitas en la cláusula.

La razón de la extensión está en que de no ser así la cláusula provocaría de forma subrepticia una alteración del equilibrio subjetivo entre precio y prestación, en el sentido de cómo se lo pudo representar el consumidor en atención a las circunstancias concurrentes en el momento de contratar ${ }^{74}$.

La Sentencia declaró abusiva y nula la cláusula suelo, por falta de transparencia, entre otras razones por las siguientes.

- Por la creación de apariencia de contrato de préstamo sujeto a interés variable, cuando de hecho y de forma previsible para el empresario son préstamos a interés mínimo fijo, sin que las oscilaciones a la baja del índice de referencia fueran aplicables para obtener una disminución del precio del dinero.

- Por ausencia de información suficiente de que se trata de un elemento definitorio del objeto principal del contrato.

La Sentencia, pese a la declaración de nulidad de la cláusula, no estimó la retroactividad de los efectos de nulidad porque generaría riesgo de trastornos graves con trascendencia al orden público económico.

\section{Artículos 6.1 y 7.1 de la Directiva. Norma de orden público y principio de efectividad}

Las respuestas del Tribunal de Justicia a cuestiones prejudiciales planteadas por órganos jurisdiccionales españoles, sobre la interpretación de la Direc-

74 SARAZÁ JimenA, R. "Las cláusulas abusivas en contratos no negociados concertados con consumidores. La abusividad de la cláusula que establece el interés de demora en préstamos personales concertados con consumidores, Cuadernos Digitales de Formación, CGPJ, Madrid, 2015, p, 12 y 13 . 
tiva 93/13, evidencian la función de control ejercida por el Tribunal sobre la compatibilidad del Derecho nacional con la Directiva, en concreto y principalmente con los artículos 6.1 y 7.1, al afirmar que las normas procesales y sustantivas de Derecho interno analizadas se oponen a la Directiva ${ }^{75}$.

El artículo $6.1^{76}$ obliga a los Estados miembros a establecer que no vincularán al consumidor, en las condiciones estipuladas por sus derechos nacionales, las cláusulas abusivas que figuren en un contrato celebrado entre éste y un profesional y dispondrán que el contrato siga siendo obligatorio para las partes en los mismos términos, si éste puede subsistir sin las cláusulas abusivas.

La jurisprudencia del Tribunal de Justicia ${ }^{77}$ afirma que artículo $6.1^{78}$ debe ser considerado como una norma equivalente a las disposiciones nacionales que en el ordenamiento jurídico interno tienen rango de normas de orden público ${ }^{79}$, consideración que extiende a todas las disposiciones de la Directiva que sean indispensables para la realización del objetivo pretendido por el artículo.

La razón está en el interés público en que se basa la protección de la Directiva, consideración que permite extender su eficacia aplicativa directa por los órganos jurisdiccionales más allá de las estipulaciones previstas en las normas nacionales.

El artículo $7.1^{80}$ impone a los Estados miembros la obligación de velar para que existan medios adecuados y eficaces para que cese el uso de cláusulas abusivas en los contratos celebrados entre profesionales y consumidores, siendo la

75 Entre otras SSTJ de 18 de febrero de 2016, Finanmadrid EFC, SA, C-49/14, de 14 de abril de 2016, Jorge Sales Sinués y Youssouf Drame Ba, asuntos acumulados C381/14 y C385/14, de 29 de octubre de 2015, BBVA, C-8/14, de 14 de marzo de 2013, Mohamed Aziz, C-415/11, de 14 de junio de 2012, Banco Español de Crédito, SA, C-618/10.

76 «Los Estados miembros establecerán que no vincularán al consumidor, en las condiciones estipuladas por sus derechos nacionales, las cláusulas abusivas que figuren en un contrato celebrado entre éste y un profesional y dispondrán que el contrato siga siendo obligatorio para las partes en los mismos términos, si éste puede subsistir sin las cláusulas abusivas.»

77 STJ de 30 de mayo de 2013, Dirk Frederik Asbeek Brusse, C-488/11, apartado 44, con cita de resoluciones anteriores, STJ de 6 de octubre de 2009, Asturcom Telecomunicaciones, C-40/08, apartado 42, y ATJ de 16 de noviembre de 2010, Pohotovost, C-76-10, apartado 50.

78 «Los Estados miembros establecerán que no vincularán al consumidor, en las condiciones estipuladas por sus derechos nacionales, las cláusulas abusivas que figuren en un contrato celebrado entre éste y un profesional y dispondrán que el contrato siga siendo obligatorio para las partes en los mismos términos, si éste puede subsistir sin las cláusulas abusivas.»

79 Sentencia de 6 de octubre de 2009, Asturcom Telecomunicaciones, C-40/08, apartado 52; y Auto de 16 de noviembre de 2010, Pohotovost', C-76/10, apartado 50.

80 «Los Estados miembros velarán por que, en interés de los consumidores y de los competidores profesionales, existan medios adecuados y eficaces para que cese el uso de cláusulas abusivas en los contratos celebrados entre profesionales y consumidores.» 
referencia «adecuadas y eficaces» manifestación positiva del principio de efectividad, inicialmente incluida en las directivas sobre antidiscriminación de los años setenta, y que con posterioridad se ha incorporado a numerosas directivas, entre ellas las relativas a consumidores como la Directiva 93/13 y la Directiva 2002/65, sobre comercialización a distancia de servicios financieros destinados a los consumidores $^{81}$, al concretar el contenido de las sanciones para los proveedores que incumplan las previsiones adoptadas por la norma nacional para aplicar la Directiva, sanciones que deberán ser efectivas, proporcionadas y disuasorias ${ }^{82}$.

\subsection{STJ de 21 de diciembre de 2016, Francisco Gutiérrez Naranjo, asuntos} acumulados C-154/15 y 307/15

El interés de la Sentencia está en que valora la adecuación a la Directiva del criterio fijado por el Tribunal Supremo en la Sentencia de 9 de mayo de 2013, ausencia de efecto retroactivo de la declaración de nulidad de cláusula suelo.

La Sentencia dio respuesta a dos cuestiones prejudiciales planteadas por el Juzgado de lo mercantil n. 1 de Granada y la Audiencia Provincial de Alicante.

El Tribunal justifica la posible valoración de las cuestiones por afectar al contenido de la información sobre cláusula que define el objeto principal del contrato y por afectar la limitación temporal de efectos al artículo 6.1.

El Tribunal afirma que la interpretación jurisprudencial establece una limitación en el tiempo de los efectos del artículo 6.1, sin que las condiciones estipuladas por los Derechos nacionales puedan afectar al contenido sustancial del Derecho a no estar vinculado el consumidor por una cláusula considerada abusiva, interpretación que priva al consumidor de obtener una restitución íntegra de las cantidades abonadas indebidamente a la entidad bancaria.

Por eso se declara la interpretación incompleta, insuficiente y un medio no adecuado y eficaz para que cese el uso de dicha cláusula, en contra de lo que establece el artículo 7.1.

${ }^{81}$ Rotr, P. «The Court of Justice's Principle of Effectiveness and its Unforeseeable Impact on Private Law Relationships», en Involvement of EU Law in Private Law Relationships, Hart, Oxford and Portland, Oregon, 2013, p. 183.

82 «Artículo 11. Sanciones. Los Estados miembros deberán prever sanciones adecuadas en caso de incumplimiento por parte del proveedor de las disposiciones nacionales adoptadas para dar cumplimiento a lo establecido en la presente Directiva. En particular, podrán disponer al respecto que el consumidor pueda rescindir el contrato en todo momento, sin gastos y sin penalización alguna. Dichas sanciones deberán ser efectivas, proporcionadas y disuasorias.» 


\section{INTERPRETACIÓN SOBRE EL CARÁCTER ABUSIVO DE LA CLÁUSULA DE INTERESES DE DEMORA Y DE VENCIMIENTO ANTICIPADO}

La STJ de 14 de marzo de 2013 (Mohamed Aziz, C-415/11) dio respuesta, entre otras cuestiones, a la relacionada con el posible carácter abusivo de cláusula de intereses de demora y de vencimiento anticipado en préstamo de ejecución bipotecaria.

La Sentencia concreta los criterios para valorar el desequilibrio teniendo en cuenta las normas aplicables de Derecho nacional para los supuestos en los que no exista acuerdo de las partes en ese sentido, mecanismo a través del cual el juez podrá valorar si el contrato deja al consumidor en una situación jurídica menos favorable que la prevista por el Derecho nacional vigente y aplicable en esos casos.

Los criterios a tener en cuenta por los órganos jurisdiccionales para valorar el carácter abusivo de las cláusulas son los siguientes.

- Intereses de demora: El contenido de las normas nacionales aplicables en defecto de acuerdo, así como el tipo de interés de demora fijado con respecto al tipo de interés legal, a fin verificar que es adecuado para garantizar la realización de los objetivos que éste persigue en el Estado miembro y que no va más allá de lo necesario para alcanzarlos.

- Vencimiento anticipado: Si la obligación incumplida por el consumidor, que faculta al profesional a dar por vencido de forma anticipada la totalidad del préstamo, tiene carácter esencial y está prevista para los casos en los que el incumplimiento tiene carácter suficientemente grave con relación a la duración y a la cuantía del préstamo. También se deberá valorar si la facultad constituye una excepción, con respecto a las normas aplicables en la materia, y si el Derecho nacional prevé medios adecuados y eficaces que permitan al consumidor poner remedio a los efectos del vencimiento anticipado del préstamo.

Como consecuencia de la STJ de 14 de marzo de 2013 se reformó la Ley Hipotecaria (LH) y la LEC, reforma que tuvo lugar mediante la Ley $1 / 2013$, de 14 de mayo.

La modificación de la LH consistió en añadir un nuevo párrafo al artículo 114 $\mathrm{LH}^{83}$, con limitación de los intereses de demora en préstamos para adquisición

83 «Los intereses de demora de préstamos o créditos para la adquisición de vivienda habitual, garantizados con hipotecas constituidas sobre la misma vivienda, no podrán ser superiores a tres veces el interés legal del dinero y sólo podrán devengarse sobre el principal pendiente de pago. 
de vivienda habitual que no podrán ser superiores a tres veces el interés legal del dinero sin posibilidad de capitalización.

La Ley también reformó el artículo 693.2 LEC $^{84}$, que hasta entonces permitía reclamar la totalidad de lo adeudado por capital y por intereses si se hubiese convenido el vencimiento total en caso de falta de pago de alguno de los plazos, modificación que introdujo la exigencia de convenio sobre el vencimiento total en caso de falta de pago de, al menos, tres plazos mensuales.

La cuestión del carácter abusivo de la cláusula de intereses de demora y de vencimiento anticipado, en los procedimientos de ejecución hipotecaria, fue tratada a nivel judicial ${ }^{85}$ con fijación de criterios de carácter orientativo.

La referencia para valorar el carácter abusivo de los intereses de demora se concretó en la previsión introducida en la nueva redacción del artículo 114 LH, así se considera abusiva la cláusula que fije intereses superiores al triple del interés legal.

La valoración del carácter abusivo de la cláusula de vencimiento anticipado se consideró no debería ser realizada en abstracto, con análisis limitado a la redacción gramatical de la cláusula. De esa forma, aunque la cláusula prevea el posible vencimiento por el impago de una cuota, no se debería declarar la nulidad si en la práctica el ejercicio de la facultad se ajustó a la nueva redacción del artículo 693 LEC que exige el impago de al menos tres cuotas.

Los criterios fijados establecen referencias legales para valorar el posible carácter abusivo de las cláusulas.

\section{Intereses de demora}

El análisis de las Sentencias de las Audiencias Provinciales posteriores a la STJ de 14 de marzo de 2013 pone de manifiesto la aplicación de criterios

Dichos intereses de demora no podrán ser capitalizados en ningún caso, salvo en el supuesto previsto en el artículo 579.2.a) de la Ley de Enjuiciamiento Civil.»

84 «2. Podrá reclamarse la totalidad de lo adeudado por capital y por intereses si se hubiese convenido el vencimiento total en caso de falta de pago de, al menos, tres plazos mensuales sin cumplir el deudor su obligación de pago o un número de cuotas tal que suponga que el deudor ha incumplido su obligación por un plazo, al menos, equivalente a tres meses, y este convenio constase en la escritura de constitución.»

85 «Jornada sobre las repercusiones de la doctrina del TJUE en materia de cláusulas abusivas en los procedimientos de ejecución hipotecara con especial referencia al régimen transitorio», celebrada en Madrid el 8 de mayo de 2013, con asistencia de Magistrados de la Sala Primera del Tribunal Supremo, de Tribunales Superiores de Justicia, Audiencias Provinciales y de Juzgados de primera instancia y mercantiles. 
distintos para interpretar el carácter abusivo de los intereses de demora, diversidad interpretativa que dio lugar a la Sentencia de Pleno del Tribunal Supremo de 22 de abril de 2015 cuyo objeto fue fijar el límite abusivo de los intereses de demora en préstamos personales, para evitar la existencia de criterios dispares entre los órganos jurisdiccionales por la elevada dosis de inseguridad jurídica que implicaba.

El Tribunal Supremo analiza las distintas referencias a intereses de demora contenidas en el artículo 1108 del Código Civil (CC) ${ }^{86}$, el artículo 20.4 de la Ley 16/2011, de 24 de junio, de Contratos de Crédito al Consumo (LCC) ${ }^{87}$, el párrafo tercero del artículo 114 de la LH tras la redacción dada por la Ley 1/2013, el artículo 20 de la Ley del Contrato de Seguro (LCS) ${ }^{88}$, el artículo $7^{89}$ de la Ley $3 / 2004$, de 29 de diciembre, por la que se establecen medidas de lucha contra la morosidad en las operaciones comerciales, y el artículo 576 LEC $^{90}$. La Sentencia concreta el objetivo de esas previsiones tendente a indemnizar al acreedor e incentivar el cumplimiento en plazo sin establecer un interés desproporcionado, con referencia a las máximas de experiencia que muestran que el interés de demora se establece por la adición de un pequeño porcentaje adicional sobre el interés remuneratorio pactado.

Finalmente, la Sala considera que el incremento de dos puntos porcentuales previsto en el artículo 576 de la LEC para la fijación del interés de mora procesal es el criterio legal más idóneo para fijar cuál es el interés de demora en los préstamos personales, estableciendo doctrina que declara el carácter abusivo de un

86 «Si la obligación consistiere en el pago de una cantidad de dinero, y el deudor incurriere en mora, la indemnización de daños y perjuicios, no habiendo pacto en contrario, consistirá en el pago de los intereses convenidos, y a falta de convenio, en el interés legal.»

87 «En ningún caso podrá aplicarse a los créditos que se concedan en forma de descubiertos a los que se refiere este artículo un tipo de interés que dé lugar a una tasa anual equivalente superior a 2,5 veces el interés legal del dinero.»

88 «4. ${ }^{\circ}$ La indemnización por mora se impondrá de oficio por el órgano judicial y consistirá en el pago de un interés anual igual al del interés legal del dinero vigente en el momento en que se devengue, incrementado en el 50 por 100; estos intereses se considerarán producidos por días, sin necesidad de reclamación judicial. No obstante, transcurridos dos años desde la producción del siniestro, el interés anual no podrá ser inferior al 20 por 100.»

89 «2. El tipo legal de interés de demora que el deudor estará obligado a pagar será la suma del tipo de interés aplicado por el Banco Central Europeo a su más reciente operación principal de financiación efectuada antes del primer día del semestre natural de que se trate más ocho puntos porcentuales.»

90 «Desde que fuere dictada en primera instancia, toda sentencia o resolución que condene al pago de una cantidad de dinero líquida determinará, en favor del acreedor, el devengo de un interés anual igual al del interés legal del dinero incrementado en dos puntos o el que corresponda por pacto de las partes o por disposición especial de la ley.» 
interés de demora que suponga un incremento de más de dos puntos porcentuales respecto del interés remuneratorio pactado en un préstamo personal, criterio que la Sentencia de Pleno de 3 de junio de 2016 extendió también a los préstamos hipotecarios.

1.1 Cuestiones prejudiciales planteadas por el Tribunal Supremo mediante Auto de 22 de febrero de 2017

Con posterioridad a las Sentencias del Tribunal Supremo de 22 de abril de 2015 y de 3 de junio de 2016, se han planteado cuestiones prejudiciales por órganos jurisdiccionales sobre la adecuación del criterio jurisprudencial expresado en las Sentencias del Tribunal Supremo con la Directiva 93/13, razón que justifica la cuestión prejudicial planteada por existir dudas objetivas sobre la interpretación de la Directiva 93/13/CEE que obligan al Tribunal Supremo a plantear cuestión prejudicial.

El Auto del Tribunal Supremo concreta las razones que justificaron el criterio fijado en las Sentencias citadas, así como los efectos asociados a la declaración, anular y suprimir completamente la cláusula de interés de demora abusiva privándola de su carácter vinculante, sin extender los efectos a la supresión de los intereses remuneratorios, intereses cuyo devengo seguirá por cumplir la función de retribuir la disposición del dinero por parte del prestatario hasta la devolución del préstamo.

En el Auto se hace referencia a este efecto, eliminación de los intereses remuneratorios por el carácter abusivo de los intereses de demora, aplicado por órganos jurisdiccionales con anterioridad a la fijación de criterio por el Tribunal Supremo en las Sentencias de 22 de abril y de 3 de junio de 2016, efecto no compartido por el Tribunal Supremo con las razones que expresa en la resolución.

El Auto hace también referencia al contenido de la cuestión planteada por uno de los órganos jurisdiccionales que ha cuestionado la compatibilidad de la jurisprudencia del Tribunal Supremo con la Directiva 93/13, sobre el riesgo de ser elevados los intereses de demora en caso de que el interés retributivo del préstamo también lo sea.

El Tribunal Supremo considera que esa posibilidad está solucionada con la doctrina de la Sala de aplicación a la Ley de 23 de julio de 1908, sobre nulidad de contratos de préstamo usurarios, que declara usurario el interés remuneratorio de un préstamo o crédito al consumo cuando es notablemente superior al normal del dinero y manifiestamente desproporcionado con las circunstancias del caso. 
Con las premisas expuestas de forma resumida, se concretan las preguntas realizadas al Tribunal de Justicia para que valore la adecuación de la doctrina jurisprudencial fijada por el Tribunal Supremo con la Directiva 93/13.

El Tribunal Supremo, de forma subsidiaria y para el caso de considerar el Tribunal de Justicia incompatible el criterio establecido, plantea cuestión sobre la compatibilidad con la Directiva 93/13 de los criterios de interpretación aplicados por órganos jurisdiccionales que tras declarar el carácter abusivo de la cláusula de intereses de demora extienden los efectos de nulidad a la eliminación también del interés remuneratorio.

\section{Vencimiento anticipado}

La mayoría de las Sentencias de las Audiencias Provinciales posteriores a la STJ de 14 de marzo de 2013 parten de considerar la validez de la cláusula de vencimiento anticipado, que ante incumplimiento de obligación por prestatario faculta al prestamista a dar por vencida la obligación de pago aplazado pactada, con criterios distintos de valoración del carácter abusivo.

Por un lado, están las resoluciones que lo identifican no con el contenido abstracto de la cláusula sino con la manera en que ha sido ejercitada, con referencia al número real y concreto de cuotas impagadas y a las concretas circunstancias de cada caso ${ }^{91}$. Por otro, están las que lo identifican con la valoración en abstracto del contenido de la cláusula en el momento de la contratación ${ }^{92}$.

\subsection{Cuestiones prejudiciales planteadas por el Tribunal Supremo mediante} Auto de 8 de febrero de 2017

La cláusula que motiva la cuestión tiene la redacción siguiente: «6. ${ }^{a}$ bis. Resolución anticipada por la entidad de crédito. La Caja (el banco), sin necesidad de requerimiento previo, podrá dar por vencido el préstamo y exigir judicialmente la totalidad de la deuda, tanto de las cantidades vencidas como pendientes de vencer, con sus intereses, demoras, gastos y costas, en los siguientes casos: a) Falta de pago de cualquiera de los vencimientos de intereses o cuotas de amortización, incluidos todos los conceptos que la

91 Acuerdo de la Junta de Magistrados de las Secciones Civiles de la Audiencia Provincial de Madrid de 30 de septiembre de 2014; Acuerdo de la reunión de Presidentes de las Secciones Civiles de la Audiencia Provincial de Barcelona, de 12 de enero de 2015.

92 Auto de Pleno jurisdiccional dictado por la Sala General de Magistrados del orden civil de la Audiencia Provincial de Pontevedra, de 30 de octubre de 2015; Auto de la Sección 7 de la Audiencia Provincial de Valencia, de 18 de diciembre de 2015. 
integran, solicitando expresamente las partes la constancia de este pacto en los libros del Registro de la propiedad, según lo dispuesto en el artículo 693 de la Ley 1/2000».

En la primera cuestión, el Tribunal Supremo, tras afirmar que no toda cláusula de vencimiento anticipado es abusiva en sí misma, plantea la posibilidad de considerar abusivo no todo el contenido de la cláusula sino únicamente parte de la misma, la que se refiere al número y entidad de los impagos que determinan el vencimiento anticipado y no a la posibilidad general de acordar el vencimiento anticipado por incumplimiento.

La duda consiste en si es posible hacer una declaración parcial del carácter abusivo de la cláusula, manteniendo la validez de la parte que no se considera abusiva. En definitiva, si es posible separar, en determinados casos, el elemento abusivo del elemento válido, de manera que este último pueda mantener su vinculación y eficacia tras la declaración de nulidad del elemento abusivo.

En la segunda cuestión se plantea, de ser declarado el carácter abusivo de la cláusula de vencimiento anticipado, la posibilidad de mantener el procedimiento de ejecución hipotecaria por ser más beneficioso para el consumidor cuando el bien hipotecado es la vivienda habitual, beneficios que no se contienen en la ejecución ordinaria de Sentencia firme dictada en juicio declarativo.

Estos beneficios, de forma resumida se concretan en los siguientes: el deudor podrá liberar el bien mediante la consignación de la cantidad debida hasta esa fecha; liberado un bien por primera vez, podrá liberarse en segunda o ulteriores ocasiones siempre que, al menos, medien tres años entre la fecha de la liberación y la del requerimiento de pago judicial o extrajudicial efectuada por el acreedor; se prevé una limitación del cálculo de las costas procesales en función únicamente de las cuotas del préstamo atrasadas, en caso de enervación de la acción ejecutiva hipotecaria; el precio a efectos de subasta no podrá ser inferior, en ningún caso, al 75 por cien del valor señalado en la tasación.

El planteamiento de la cuestión por el Tribunal Supremo ha motivado la adopción de acuerdos en distintas Audiencias Provinciales ${ }^{93}$ para suspender los procedimientos en trámite que puedan verse afectados por la respuesta del Tribunal de Justicia.

93 Acuerdo de la Audiencia Provincial de Barcelona de 10 de febrero de 2017; de la Audiencia Provincial de Madrid de 14 de febrero de 2017 y de la Audiencia Provincial de Castellón de 15 de febrero de 2017. 


\section{CONCLUSIONES}

La limitación de eficacia aplicativa de la Directiva 93/13, sin efecto directo horizontal en las relaciones jurídicas entre particulares, y la inexistencia de normas de procedimiento a nivel europeo que regulen de forma uniforme la forma de hacer valer los Derechos surgidos de la Directiva, lleva implícita una limitación normativa para la armonización de la protección de consumidores a nivel europeo, limitación que se incrementa con el distinto grado de incorporación de la norma europea en los Estados miembros como ya detectó la Comisión en 2008, situación prolongada en el tiempo.

La limitación e insuficiencia normativa, y la falta de coordinación para concretar qué y cómo conseguir la protección de consumidores, se pretende suplir por vía jurisdiccional, situación que da lugar a criterios de interpretación distintos, con la incidencia que eso tiene en la seguridad jurídica que pretende garantizar la protección del consumidor, criterios que además parecen estar sujetos a continua revisión por estar ante normas programáticas que pretenden alcanzar un resultado indeterminado consistente en un nivel elevado de protección.

La complejidad de la vía jurisdiccional se intensifica por intervenir el Tribunal de Justicia mediante una función de revisión de control de ajuste de las normas de Derecho interno y de los criterios de interpretación adoptados judicialmente, sin concretar de forma definitiva si una cláusula es abusiva y hasta donde debe llegar la protección, ausencia de concreción que permite cuestionar de forma continua las normas y los criterios fijados para llevar la protección de consumidores más lejos.

Title:

Effectiveness of European Union Law v. Constitutional principle of the rule of law.

\section{Summary:}

I. Introduction. II. The protection of consumers in the Treaties and in the Spanish Constitution of 1978. III. Principle of effectiveness and right to effective judicial protection. IV. The directive, legal instrument for harmonization. V. Council Directive 93/13/EEC of 5 April 1993 on unfair terms in consumer contracts. VI. Interpretation of the abusive nature of the interest for delayed payment and early maturity clause. VII. Conclusions. 


\title{
Resumen:
}

Las Sentencias dictadas en los últimos años por el Tribunal de Justicia de la Unión Europea, en respuesta a cuestiones prejudiciales sobre la adecuación de las normas aplicables en el ordenamiento jurídico español para alcanzar los objetivos fijados en la Directiva 93/13, sobre cláusulas abusivas en contratos celebrados con consumidores, ponen de manifiesto la oposición de algunas de las normas analizadas a la Directiva. Esto traslada la obligación de conseguir los resultados a los órganos jurisdiccionales y da lugar en la práctica a la existencia de criterios de interpretación diferentes ante premisas fácticas idénticas, en perjuicio de la pretendida seguridad jurídica que garantice la confianza de los consumidores en la contratación.

\begin{abstract}
:
The rulings handed down in recent years by the Court of Justice of the European Union, in response to preliminary rulings on the adequacy of the rules applicable in the Spanish legal system to achieve the objectives set out in the Directive 93/13 on unfair terms in consumer contracts, highlight the opposition of some of the rules analyzed to the Directive. This moves the obligation of results for the courts and gives rise in practice to the existence of different criteria of interpretation before identical factual premises, to the detriment of purported legal certainty that ensures the confidence of consumers in the hiring.
\end{abstract}

\section{Palabras clave:}

Principio efectividad; imperio ley; tutela judicial efectiva; oposición Directiva 93/13; abusiva; de oficio; seguridad jurídica; interés demora; vencimiento anticipado.

\section{Keywords:}

Principle effectiveness; rule law; effective judicial protection; opposition Directive 93/13; unfair; ex officio; legal certainty; interest delayed payment; early maturity clause. 